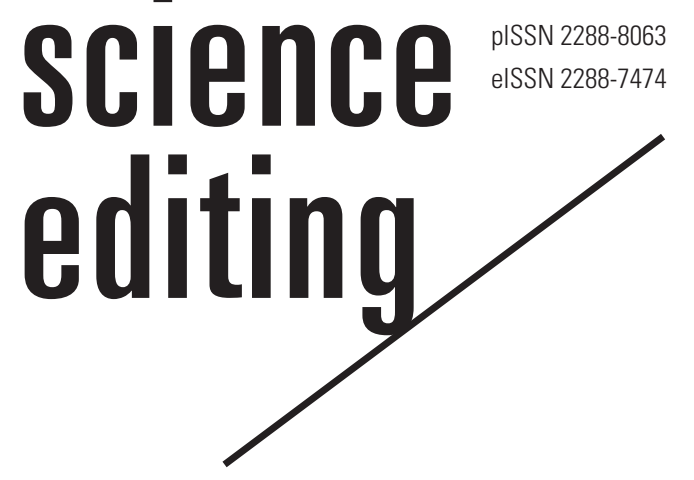

\title{
Bibliometric analysis and visualization of Islamic economics and finance articles indexed in Scopus by Indonesian authors
}

\author{
Luqman Hakim Handoko, ${ }^{1,2}$ \\ ${ }^{1}$ School of Islamic Economics SEBI, Depok, Indonesia; ${ }^{2}$ Kulliyyah of Economics and Management Science, \\ International Islamic University Malaysia, Kuala Lumpur, Malaysia
}

\section{Abstract}

Purpose: This study aimed to analyze the bibliometric characteristics and trends of articles on Islamic economics and finance (IEF) indexed in Scopus by Indonesian authors.

Methods: Data were retrieved from the Scopus database. Articles were searched in June 2020 with the limitation of Indonesian authors or affiliation. The keywords used in this study included IEF, and variations thereof, with the search filtered by Indonesian affiliation. Simple statistical methods were used, and a bibliometric analysis was conducted using VOSviewer software. This study visualized patterns of the co-occurrence of keywords, citations of documents, co-citation relationships, and bibliographic coupling.

Results: The number of studies in the field of IEF increased in recent years. Articles on IEF have been published in more than 150 journals, among which the most popular was Talent Development and Excellence. Collaboration among authors reached 33 countries, most prominently Malaysia. Certain keywords, such as halal tourism, zakat, and Islamic microfinance, have become the most popular in the last few years. The bibliometric analysis showed that 24 documents had the largest citation relationship, 52 journals had the largest co-citation network, and 172 documents had the largest bibliographic coupling relationship.

Conclusion: Research in the field of IEF by Indonesian authors has increased rapidly, with extensive collaboration. Halal tourism is among the most popular research topics in the last few years and is a prospective topic for future research. Moreover, the results showed that sources on IEF were widely used as references.

Received: July 2, 2020

Accepted: July 15, 2020

Correspondence to Luqman Hakim Handoko

lukman.hakim.handoko@sebi.ac.id

ORCID

Luqman Hakim Handoko

https://orcid.org/0000-0003-0973-6607
Keywords

Bibliometric analysis; Indonesia; Islamic economics and finance; Scopus databases; VOSviewer
This is an open access article distributed under the terms of the Creative Commons Attribution License (https://creativecommons.org/licenses/by/4.0/). which permits unrestricted use, distribution, and reproduction in any medium, provided the original work is properly cited. 


\section{Introduction}

Background/rationale: Economic studies based on Islamic principles, a field that has subsequently become known as Islamic economics and finance (IEF), experienced a resurgence starting around 5 or 6 decades ago. Chapra discussed four fundamental elements (vision, mechanism, methods, and worldview) to demonstrate the differences between Islamic economics and conventional economics [1]. Likewise, Indonesia, as the world's largest Muslim country, has not been left behind in studies of IEF. The idea of the Islamic economy was introduced in Indonesia approximately in the early 1980s [2]. However, IEF in Indonesia developed rapidly in the last 2 decades. Educational programs in the field of IEF have been established by universities starting from the undergraduate and extending to doctoral level. Research on IEF has been published in numerous national and international journals in the last decade. Based on the Indonesian journal database (Garba Rujukan Digital, http://garuda.ristekbrin.go.id), there are approximately 150 journals on IEF. These observations document the rapid growth of IEF research in Indonesia.

Nevertheless, the growth of IEF articles by Indonesian authors that are indexed by Scopus needs further research. The question is whether the growth of articles on IEF published in qualified, Scopus-indexed journals matches the growth of research published in Indonesian journals. Based on the latest research, $66.5 \%$ of Indonesian researchers are familiar with Scopus, but unfortunately, $76 \%$ of them have never published an article in journals indexed by Scopus [3]. However, in the 2010s, a new regulation made Scopus publication an important criterion for higher education assessment [4]. This regulation might urge lecturers to conduct research and to publish articles in journals indexed by Scopus. For this reason, it is necessary to explore the current state of IEF articles in Scopus-indexed journals by Indonesian authors or authors with Indonesian affiliation. To the best of the author's knowledge, this issue has yet to be investigated, although a recent study presented a bibliometric analysis of IEF articles that were indexed in the SINTA database [5].

Objectives: This study aimed to analyze the bibliometric characteristics and trends of IEF articles by Indonesian authors in the Scopus database. These findings may provide useful data for researchers to understand trends in research and to discover the novelty of their research in the field of IEF.

\section{Methods}

Ethics statement: This was not a human subject study; therefore, neither institutional review board approval nor informed consent was needed.
Study design: This was a literature database-based descriptive bibliometric study.

Setting: A bibliometric analysis was conducted to observe the distribution of articles on IEF by Indonesian authors. Data were retrieved from the Scopus database in June 2020. This study primarily used the Scopus document search option with the period set as "all years." The results were filtered by setting Indonesia as the affiliation country to identify authors from Indonesia or affiliated with any institution in Indonesia.

The first step was defining the keywords to use. To incorporate all aspects of IEF, the study used separate keywords such as "halal industry/tourism," "Islamic capital market," "Islamic banking," "Islamic finance," "Islamic microfinance," "Islamic insurance," "zakat," "waqf," "Islamic accounting," "Islamic marketing," and "Islamic fintech." The second step, after finalizing the keywords, was finding the articles from the Scopus database. The search was limited to journal articles and conferences with authors from Indonesia. The initial search found 649 documents.

The third step was refining the initial results by excluding duplicate documents, which led to the identification of 559 relevant documents. Finally, the data analysis process was conducted by using the VOSviewer software to analyze and visualize co-authorship, citation analysis, co-occurrence, cocitation, and bibliographic coupling.

Statistical methods: Descriptive statistical analyses were carried out to present the timeline and distribution of the articles.

\section{Results}

Based on the data retrieved from the Scopus database, the first finding was the trend in the number of papers on IEF published in Scopus. The first paper appeared in Scopus in 2004 (one article). As shown in Fig. 1, there was a stable increase in the number of papers published in Scopus-indexed journals from 2004 to 2014. However, in the last 5 years, the number of papers published has increased rapidly. Therefore, 2015 may have been a turning point in authors' interest in publishing in Scopus indexed journals.

Fig. 2 shows the most 24 popular journals among Indonesian authors for publishing articles on IEF. Of 559 published articles, almost half $(\mathrm{n}=268,47.9 \%)$ were published in these 24 journals. In contrast, the other 291 articles (52.1\%) were scattered across more than 100 journals that published four or fewer articles each. As shown in Fig. 2, the most popular journal was Talent Development and Excellence with 35 articles (6.26\%), and the last place among the 24 most popular journals was jointly occupied by Academy of Strategic Management Journal and Advanced Science Letters, with five articles each (0.89\%). Additionally, based on the Scimago journal 


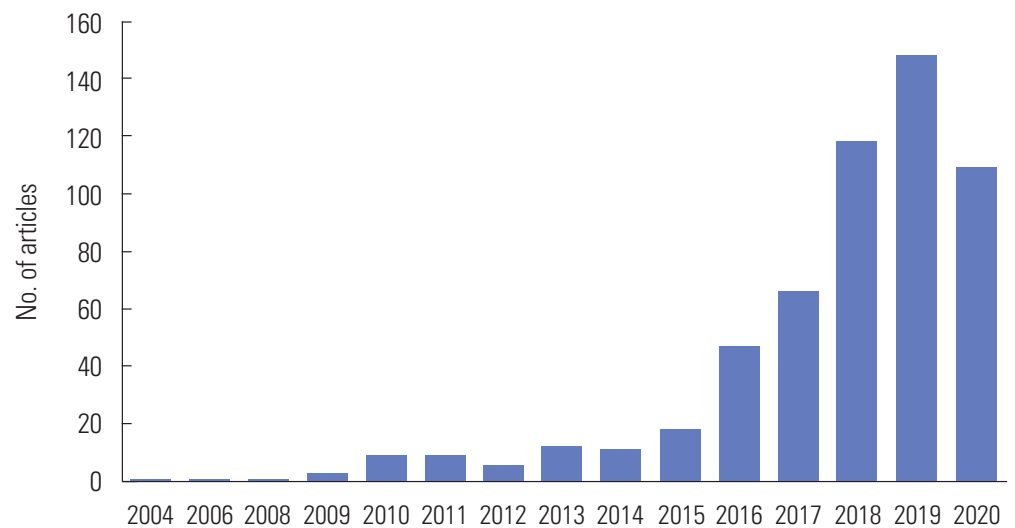

Year

Fig. 1. Yearly trends in articles on Islamic economics and finance by Indonesian authors.

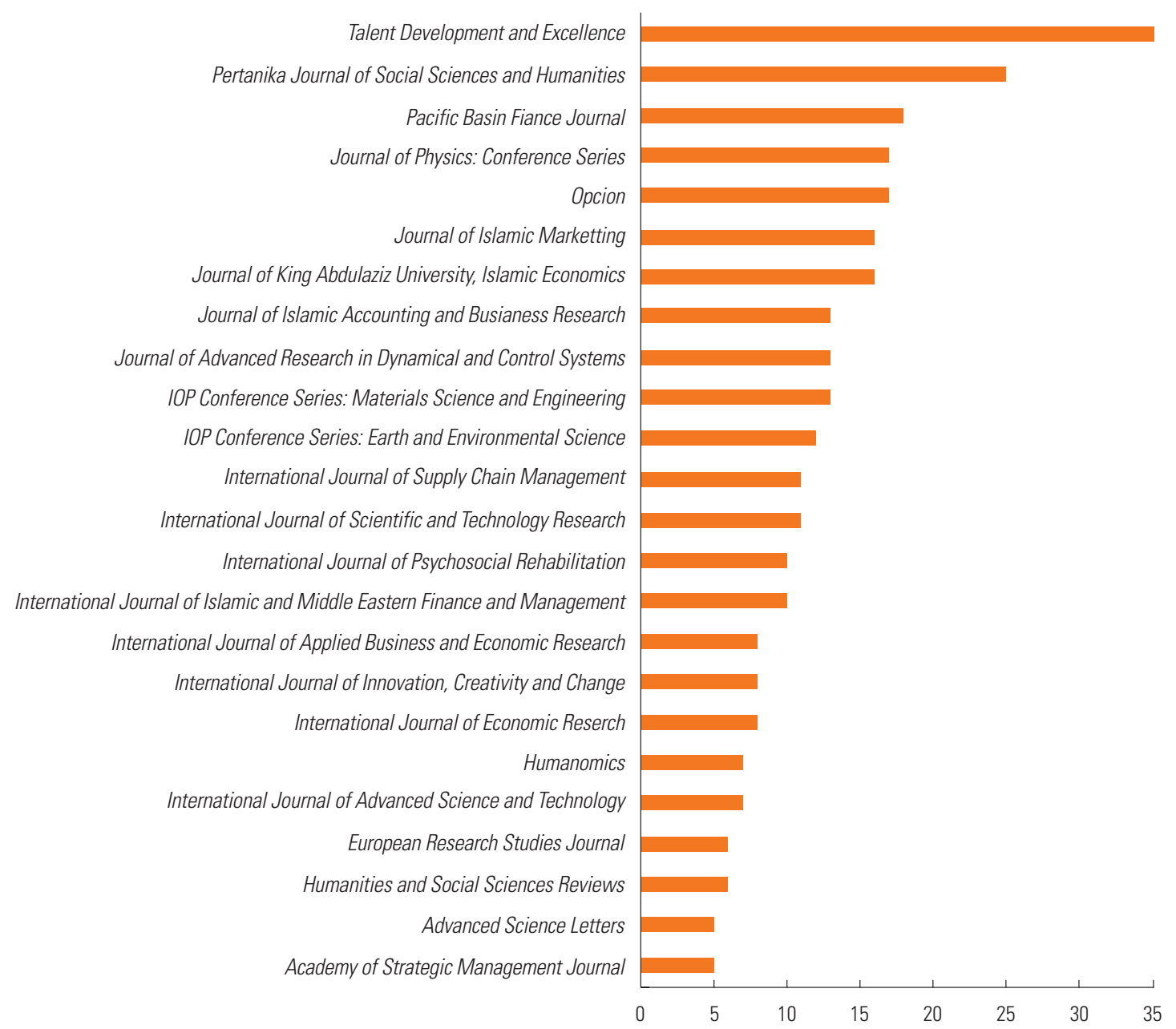

Fig. 2. Top 24 journals and their publishers. 


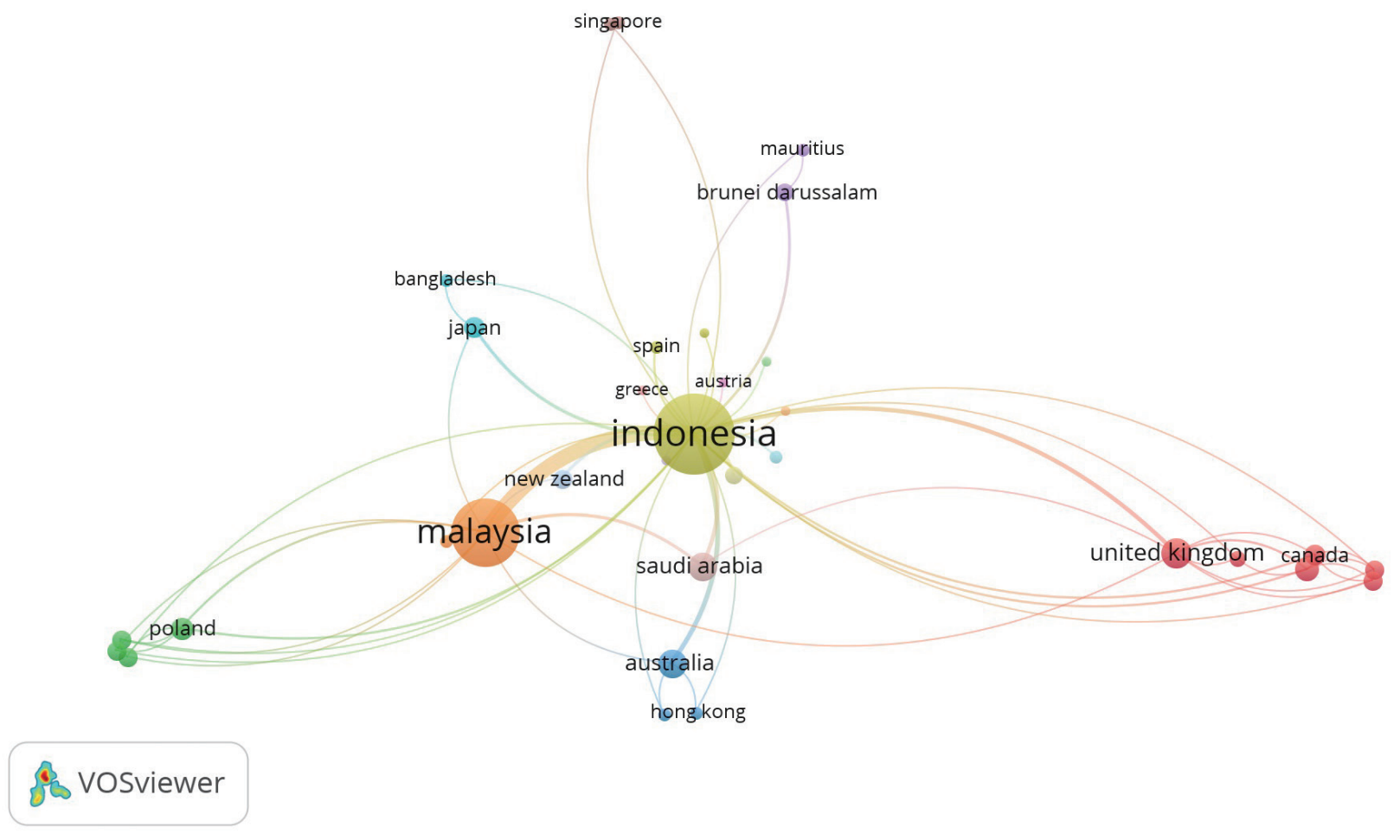

Fig. 3. The co-authorship network of articles on Islamic economics and finance in terms of countries.

ranking (Suppl. 1), there were 10 Q3 journals, six Q2 journals, five Q4 journals, and one Q1 journal, whereas two still did not have a Scimago journal ranking assigned.

The next step was visualizing the data on IEF articles in terms of co-authorship-related countries, co-occurrence-related author keywords, citation-related publication sources, co-citation-related publication sources, and bibliographic coupling. The first visualization was co-authorship related to countries. The purpose of country co-authorship analysis was to determine the degree of communication and influence between countries in the field of IEF. The distribution map of the country co-authorship network of IEF is shown in Fig. 3. The co-authors of IEF articles from Indonesia had affiliations with 33 countries. The colors of the nodes represented the diversification of the research field, which formed 17 clusters.

In Fig. 3, the large nodes denote significant countries. Links between nodes indicate the relationships among countries, and the thickness of the link and distance between the nodes show the level of collaboration between countries. As shown in Fig. 3, the center of the network is Indonesia, since the articles were written by Indonesian authors. The main countries of collaboration were Malaysia, Australia, Saudi Arabia, and England. The strength of the link between Indonesia and Malaysia was 93, while the strengths of the links between Indonesia and Australia, England and Saudi Arabia were 9, 7, and
13 respectively. Additionally, an overlay visualization indicates that recent collaboration mostly came from Bahrain, followed by Poland, Japan, Pakistan, and Spain.

The distribution map of keywords in the IEF articles is presented in Fig. 4. When the 1,503 keywords were filtered using a minimum appearance of 5 times, 43 keywords met the threshold. The size of the nodes and words in Fig. 4 represents the weights of each keyword with larger size indicating a greater weight. The keyword "Indonesia" was the most common, occurring 60 times followed by Islamic banking" (53), "zakat" (34), and "halal tourism" (19), "Islamic bank" (19), and "religiosity" (19). More detailed information on the keywords is presented in Suppl. 2.

Furthermore, the distance between nodes reflects the strength of the relationship between those nodes. A shorter span indicates a stronger connection. A link between two keywords indicates that they appeared together, while the thickness of the link shows the density of co-occurrence. Nodes with the same color belong to a cluster. As shown in Fig. 4, the node "Indonesia" had thick lines connecting it with "Islamic banking" (9), "Islam" (8), "Malaysia" (4), "bank" (4), and "halal tourism" (2). The node "Islamic banking" had thick links with "Indonesia" (9), "service quality" (5), "customer satisfaction" (4), and "performance" (3). The keywords of IEF articles were divided into 7 clusters. VOSviewer also 


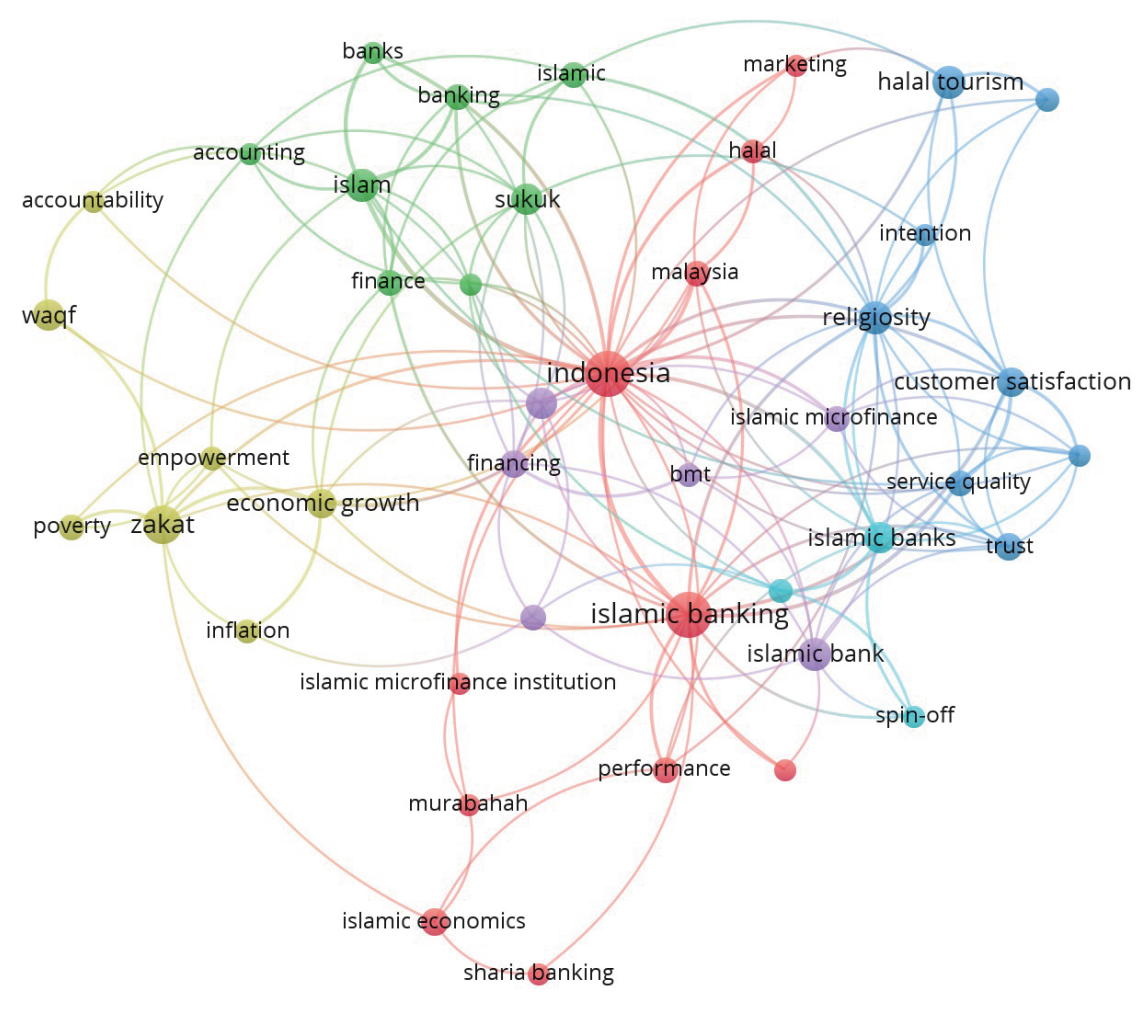

Fig. 4. The co-occurrence network of keywords in articles on Islamic economics and finance.

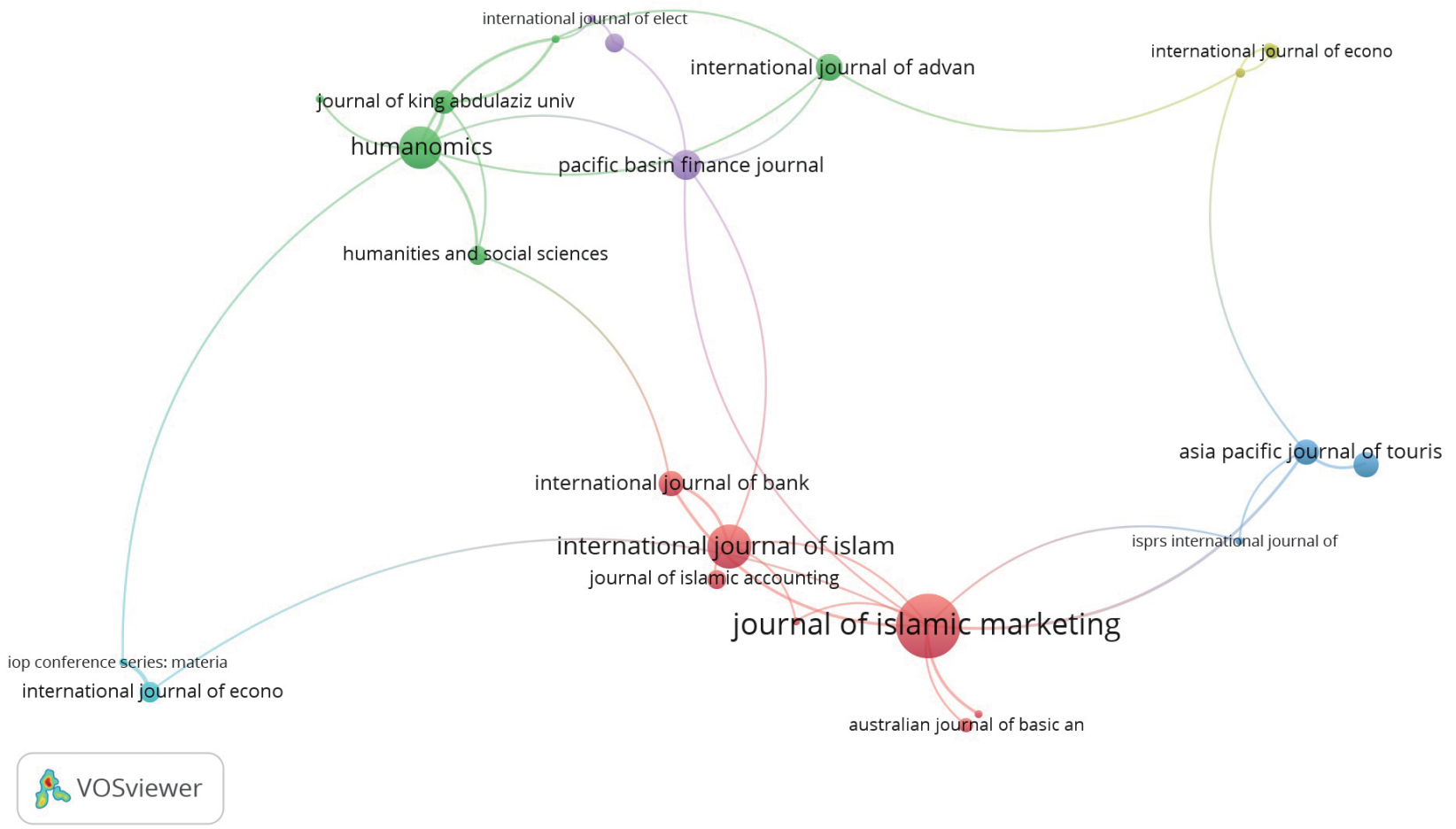

Fig. 5. The citation network of articles on Islamic economics and finance in terms of publication source. 


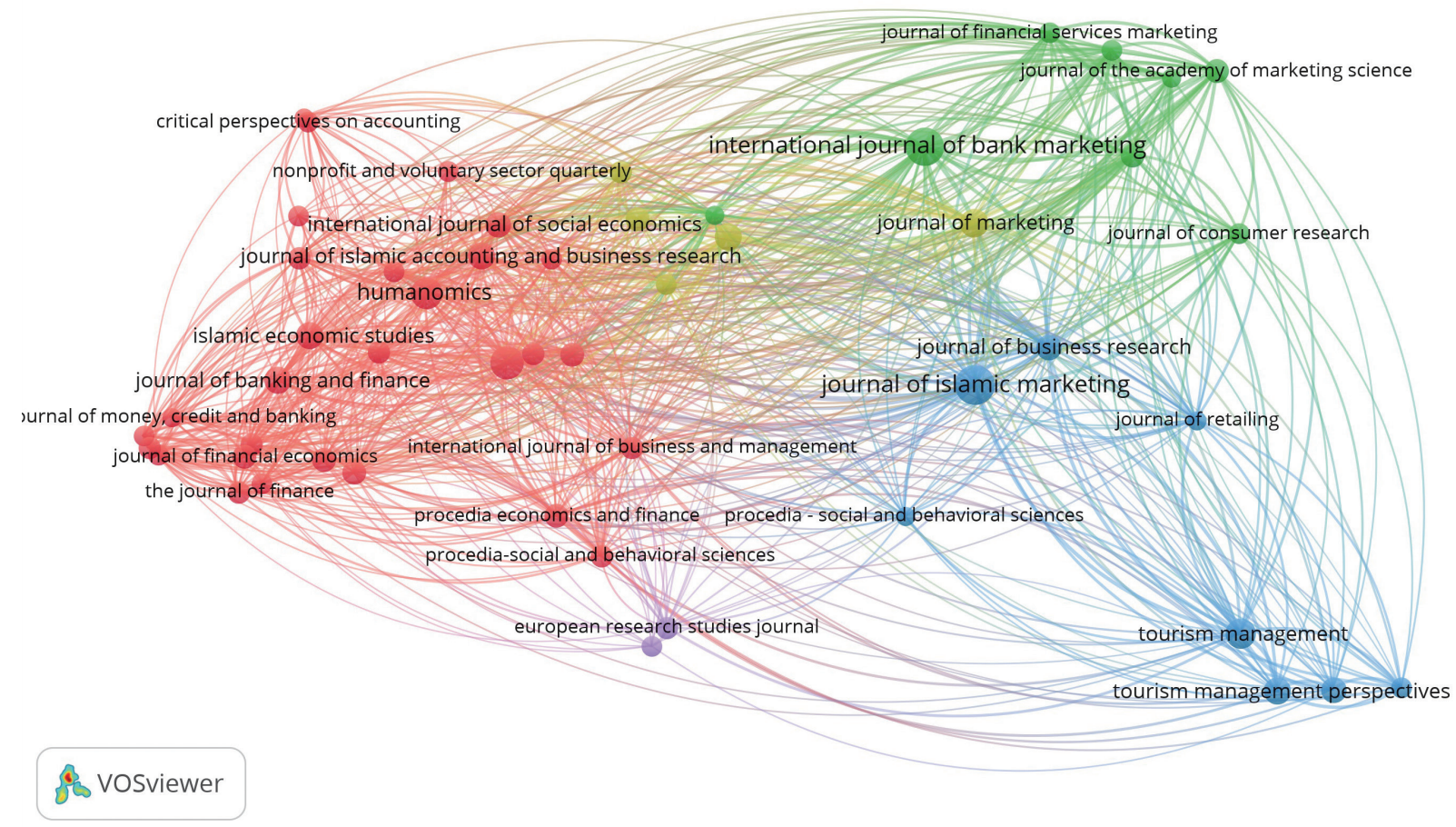

Fig. 6. The co-citation network of articles on Islamic economics and finance in terms of publication sources.

provided an overlay visualization of trends in keyword appearance. Recently, appearing keywords included halal tourism, Islamic tourism, religiosity, inflation, performance, customer loyalty, and Islamic microfinance institution.

Based on VOSviewer, there were 175 sources. However, when a filter was applied to sources with at least one document and two citations, 84 sources met the threshold and VOSviewer divided them into 6 clusters. Of 84 sources that met the threshold, only 24 documents had strong connections between each other, as shown in Fig. 5. The colors of the nodes correspond to separate clusters that were assigned. The size of a node denotes the number of citations received by the sources. The thickness of links and the distance of the nodes indicated the closeness and strength of the relationship between the nodes. Thicker nodes and closer distances indicate more frequent and stronger relationships. As shown in Fig. 5, the most commonly cited journal by authors was the Journal of Islamic Marketing with 180 citations of 25 documents, and it had 9 links and a total link strength of 12. The International Journal of Islamic and Middle Eastern Finance and Management placed second with 81 citations of 17 documents, and it had 5 links and a total link strength of 6 . The Humanomics journal followed, with 78 citations of 13 documents, and it had 7 links and a total link strength of 11 . The other details on the top 10 sources by citation number are shown in Suppl. 3.
Based on VOSviewer, there were 10,484 sources. When filtered with a minimum co-citation count of 20,52 sources met the threshold. Fig. 6 shows 52 nodes representing the journal co-citation network. The size of the node indicates the frequency of the journal and the number of published articles. As shown in Fig. 6, the distance between two nodes reflects the closeness of the relationship of the journals. The closer two journals are, the greater the co-citation frequency is. The colors of the nodes designate 5 clusters. The most active journal in the red cluster was the International Journal of Islamic Middle Eastern Finance and Management which had 45 links, 125 citations, and a total link strength of 1,212. The most active journal in the blue node was the Journal of Islamic Marketing. The journal had 39 links, 219 citations, and a total link strength of 2,408. The most active journal in the green node was the International Journal of Bank Marketing, which had 44 links, 182 citations, and a total link strength of 3,336. The most active journal in the yellow node was the Journal of Business Ethics, with 44 links, 60 citations, and a total link strength of 816. Finally, the most active journal in the purple node was the European Research Studies Journal, which had 26 links, 33 citations, and a total link strength of 167.

The last meta-analysis was the bibliographic coupling analysis. Of the 559 articles on IEF, 221 met the threshold of having at least one citation. However, not all of documents were 


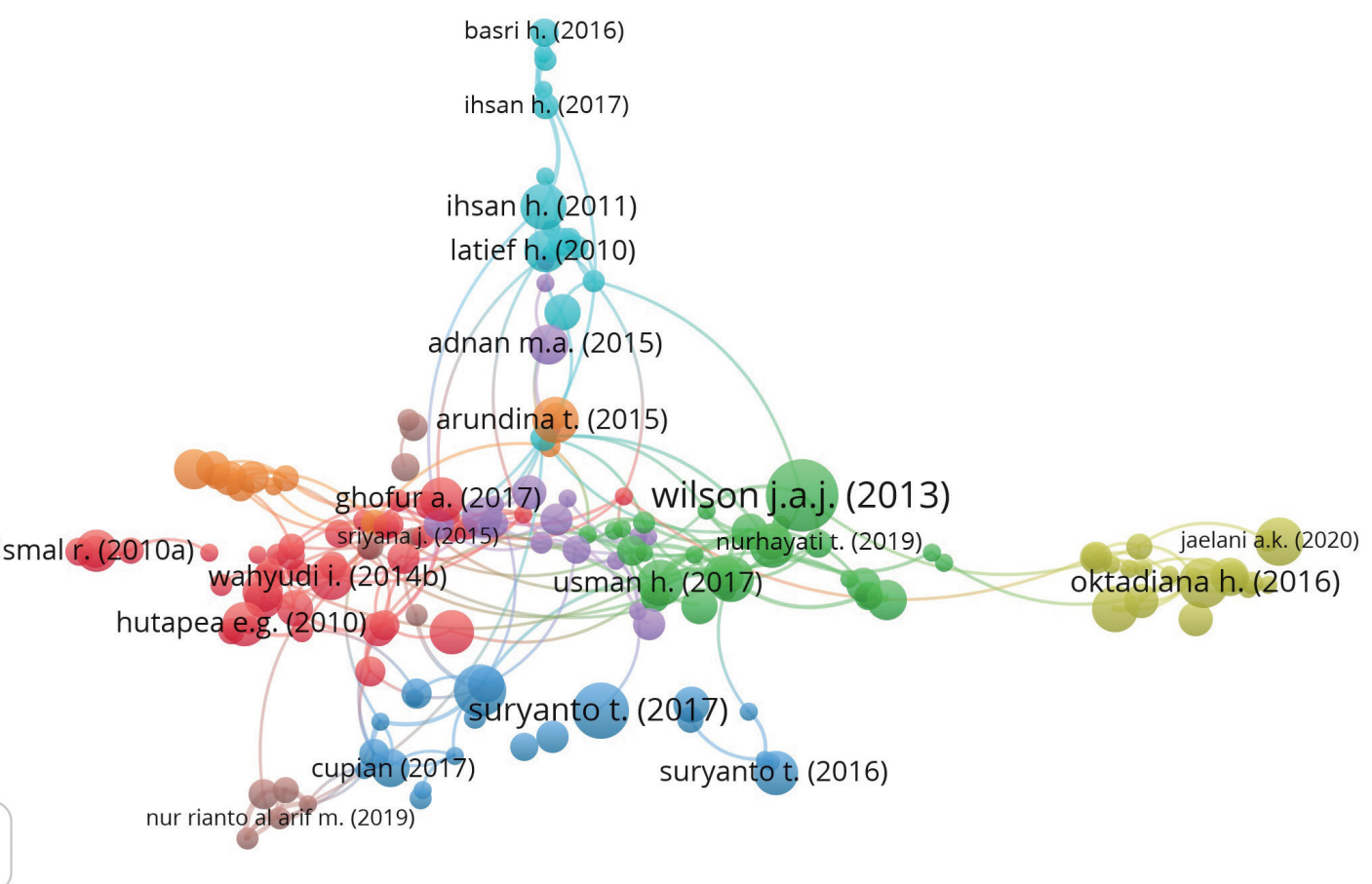

Fig. 7. The bibliographic-coupling network of articles on Islamic economics and finance.

connected, and the largest network contained 172 documents, as shown in Fig. 7. The documents were divided into 13 clusters, which are represented by the colors of the nodes. In the visualization presented in Fig. 7, each node represented an author or a group of authors. Larger nodes indicate more influential author(s). As shown in Fig. 7, Wilson et al. (2013) were the most influential author with seven links, a total link strength of 8 , and 91 citations, followed by Suyanto et al. (2017) (four links, a total link strength of 2 , and 40 citations); Oktadiana et al. (2016) (eight links, a total link strength of 6, and 27 citations). The distance between two nodes, represents the closeness of the relationship between two researchers. In other words, authors close to each other tend to cite the same articles.

\section{Discussion}

The above results show the detailed bibliographic characteristics of articles on IEF published by Indonesian authors in Scopus-indexed journals. IEF research has grown quite rapidly in the last few years. This shows that the international publication of IEF research has grown in parallel with the increasing number of domestic publications. Based on the journals where the articles were published, it can be seen that research on IEF has been widely accepted by the scientific community throughout world. The variety of journals also indicates the diversity of topics discussed in the field of IEF.

The analysis of co-authorship relationships showed co-authorship relationships with researchers from more than 30 countries. This means that Indonesian authors actively collaborated with researchers from other countries. Malaysia, Saudi Arabia, and the UK had the most frequent collaborations. These countries actively offer education at the doctoral level and are centers of IEF studies. However, it was interesting to note that Australia, which was the country with the second-highest number of collaborators, has no specific educational programs or centers related to IEF studies. Nonetheless, these findings may be due to the close relationship between these two countries and the fact that many students who pursue doctoral-level studies in that country specialize in IEF.

The analysis of the co-occurrence of keywords showed the patterns and relationships between keywords appearing together in an article. The pattern of these keywords makes it easier for the researcher to identify novel research patterns. As mentioned previously, a focus of recent research has been $h a$ lal practices or halal tourism. Therefore, for example, as shown in Fig. 4, there is a wide scope for research on how halal practices or halal tourism is related to economic growth. Accordingly, areas related to halal practices or halal tourism, such as zakat or waqf, Islamic banking, or Islamic microfinance also have a wide scope for future research. 


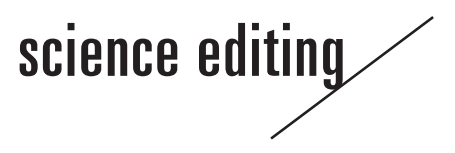

Figs. 2 and 5 show that there was no direct correlation between the number of publications in a certain journal and the number of citations. For example, although the Journal of Islamic Marketing was ranked sixth in terms of publications, it was ranked first in terms of the number of citations. Interestingly, even though Talent Development and Excellence was the top journal that published articles on IEF, it had no records in the citation network. This result also seems to indicate that the Scimago journal ranking by Scopus tended to influence the level of citations among the articles. Based on the results of the co-citation network, from more than 10,000 sources, only approximately 50 sources met the co-citation threshold of 20. This indicates that various sources on IEF were available for references. Furthermore, bibliography coupling-related documents indicated the closeness and patterns of influence of the articles. Of the 559 documents, 221 had a network, but only 172 had networks of a strong relationship, while the remaining 338 documents had no network.

Limitation: However, this study is not free from limitations. This study was limited to five bibliometric analyses, which focused on analyses of single types of units; therefore, many angles remain to be explored. The keyword search used only general keywords, so some relevant articles might have been missed. Thus, further research might broaden the types of units that are analyzed, include more detailed keywords, and expand the scope of databases to include others, such as Web of Science.

Conclusion: The results statistically showed that the number of articles on IEF published in Scopus-indexed journals has increased, especially in the last decade. Furthermore, the results show that authors have wide-open opportunities to collaborate with researchers from other countries. It seems that halal practices or halal tourism is a trending topic in recent years, which provides a major opportunity for further research. Additionally, the results showed that sources on IEF research are extensively available and accessible for future research.

\section{Conflict of Interest}

No potential conflict of interest relevant to this article was reported.

\section{Data Availability}

Dataset file is available from: the Harvard Dataverse at: https:// doi.org/10.7910/DVN/YGWA06

Dataset 1. Raw data of IEF articles

\section{Supplementary Material}

Supplementary file is available from the Harvard Dataverse at: https://doi.org/10.7910/DVN/YGWA06

Suppl. 1. List of top 24 journals on Scimago journals ranking

Suppl. 2. List of keywords

Suppl. 3. List of 30 journals based on total citations

\section{References}

1. Chapra MU. Is it necessary to have Islamic economics? J Socio-Econ 2000;29:21-37. https://doi.org/10.1016/S10535357(00)00051-2

2. Choiruzzad SA, Nugroho BE. Indonesia's Islamic economy project and the Islamic scholars. Procedia Environ Sci 2013;17:957-66. https://doi.org/10.1016/j.proenv.2013.02.114

3. Ahmar AS, Kurniasih N, Irawan DE, et al. Lecturers' understanding on indexing databases of SINTA, DOAJ, Google Scholar, Scopus, and Web of Science: a study of Indonesians. J Phys Conf Ser 2018;954:012026. https://doi. org/10.1088/1742-6596/954/1/012026

4. Prasojo LD, Fatmasari R, Nurhayati E, et al. Indonesian state educational universities' bibliometric dataset. Data Brief 2019;22:30-40. https://doi.org/10.1016/j.dib.2018.11.128

5. Firmansyah EA, Faisal YA. Bibliometric analysis of Islamic economics and finance journals in Indonesia. AL-MUZAR'AH 2019;7:17-26. https://doi.org/10.29244/jam.7.2.17-26 